
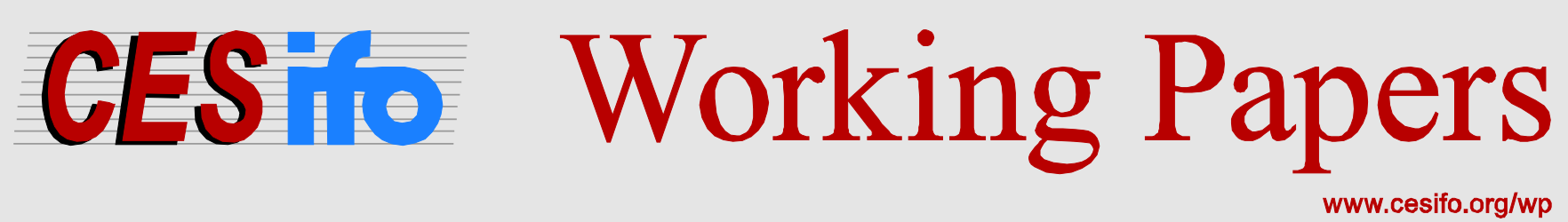

\title{
Price Effects on Compound Commodities
}

\author{
Junichi Minagawa \\ Thorsten Upmann
}

CESIFO WORKING PAPER NO. 6060

CATEgORY 1: PUBLIC FinANCE

August 2016

An electronic version of the paper may be downloaded

- from the SSRN website:

- from the RePEc website:

- from the CESifo website: wWw.SSRN.com

Www.RePEc.org

www.CESifo-group.org/wp 


\title{
Price Effects on Compound Commodities
}

\begin{abstract}
We explore effects of simultaneous price changes for the demand of a group of goods, which we refer to as a compound commodity. Specifically, we consider unit and proportional cost components (e. g., taxes, transportation costs, etc.) imposed on the compound commodity. We find that there is a serious aggregation problem implying that the property of a downwardsloping demand curve does not generally hold for the demand of a compound commodity. Notably, both substitution effects of the unit cost and of the proportional cost for a compound commodity may be unambiguously opposed. Finally, we apply these results to commodity taxation.
\end{abstract}

JEL-Codes: D010, D110, H200.

Keywords: demand for a group of goods, compound commodity, unit and proportional costs, income and substitution effects, Slutsky equation, Giffen goods.

Junichi Minagawa

Faculty of Economics

Chuo University

742-1 Higashinakano

Japan - Hachioji, Tokyo 192-0393

minagawa@tamacc.chuo-u.ac.jp
Thorsten Upmann

Bielefeld University

Faculty of Business Administration and

Economics, Postfach 100131

Germany - 33501 Bielefeld

TUpmann@wiwi.uni-bielefeld.de 


\section{INTRODUCTION}

In the classic demand theory, it is accepted as fundamentally true that the substitution effect of an increase in the price of a good always decreases the demand for that good. However, in practice, price changes frequently occur for a group of goods rather than for a single good, and therefore it may be useful to analyze the substitution effects caused by simultaneous price changes for a group of goods. In particular, by considering two types of simultaneous, parallel price changes, we find that the above property for the demand of a single good does not generally hold for the demand for a group of goods in economically meaningful situations. Thus, we face a serious aggregation problem.

Clearly, aggregation is a significant and long discussed issue in economics, and may be traced back, at least, to Hicks: when the total expenditure on a group of goods can be treated as a single good, this group is referred to as a composite commodity-a result well known as Hicks' (1939) composite commodity theorem. The fundamental condition for this theorem to hold is that the prices of these goods change proportionally in such a way that the relative prices within this group are kept constant. ${ }^{1}$ Yet, non-proportional price changes are, as we shall argue, a common phenomenon, even if such changes result from common cost components included in all of these prices. Furthermore, little is known about how the total demand (rather than the expenditure) for a group of goods is affected by simultaneous price changes, especially by those which alter relative prices. Therefore, in this paper, we explore the effects of parallel, non-proportional price changes on the total demand for a group of goods.

The basic idea of our arguments is as follows. A per unit cost added to the prices of two goods decreases the relative price of the more expensive good and hence leads to a relative increase in the compensated demand for that good. This

${ }^{1}$ There are many studies which have formalized, generalized, and tested the composite commodity theorem (see, e. g., Samuelson, 1947; Katzner, 1970; Green, 1976; Deaton and Muellbauer, 1980; Carter, 1995; Lewbel, 1996; Moro, 2001; and Davis, 2003). 
observation was first made by Alchian and Allen (1964, pp. 74-75). Then, holding the unit cost unchanged, a proportional cost added to both prices increases the relative price of the more expensive good and hence leads to a relative decrease in the compensated demand for that good. This implication was suggested and tested by Hummels and Skiba (2004). In the literature on the Alchian-Allen theorem, both cost components are variously specified: the common unit cost component is interpreted as a per unit tax, a transportation fee, a wage (opportunity cost of leisure), etc., whereas the common proportional cost component is interpreted as an ad valorem tax, an iceberg transportation cost, a mark-up rate, etc. $^{2}$

While these substitution effects for relative demand provide valuable insights, the substitution effects induced by changes in the common unit and proportional cost components for the total demand of a group of goods also have important implications. It is already known that the effect of an increase in the unit cost on the total compensated demand for a group of goods (i. e., the substitution effect of a unit cost for total demand) is non-positive (see Silberberg and Suen 2001, pp. 335-336). In this paper, we show that the effect of an increase in a proportional cost component on the total compensated demand for a group of goods (i.e., the substitution effect of a proportional cost for total demand) is basically opposite to that of a unit cost. (We also refer to the total demand for a group of goods as the group demand.) In particular, both substitution effects are unambiguously opposed either when all goods are subject to the unit and proportional cost components or when a group of goods and the other goods are 'on average' not substitutes.

This general implication has also practical relevance, for example, for tax policies. Governments often aim at reducing total consumption of demerit goods

${ }^{2}$ Further details and development on this topic can be found in, e. g., Minagawa and Upmann (2015). 
such as cigarettes and alcohol, or environmentally harmful products; or at increasing total consumption of merit goods such as sporting activities, or consumption of cultural goods. (The concept of (de)merit goods was introduced by Musgrave, 1959, pp. 13-14.) Our results then suggests that the substitution effects induced by a higher unit tax imply less group demand, while the substitution effects induced by a higher ad valorem tax lead to more group demand. Consequently, provided that income effects can be neglected, a government aiming at reducing (or increasing) group demand always has a suitable tax instrument at hand, assuming that both unit taxes and ad valorem taxes are institutionally feasible.

The positive substitution effect of the proportional cost is surprising at first sight, but is in fact quite intuitive. Suppose that there are only two goods, both of which are subject to unit and proportional costs. Then, since an increase in the proportional cost increases the relative price of the more expensive good, a consumer substitutes the less expensive good for the more expensive good. But then, because of the exchange rate, the consumer gives up one unit of the more expensive good in exchange for getting more than one unit of the less expensive good; therefore, this substitution leads to an increase in the sum of the compensated demands for the two goods.

In a second step, we extend the analysis by taking into account income effects. We show that since unit and proportional cost components induce basically opposite substitution effects, the presence of income effects strengthens the negative effect of the unit cost component, but mitigates the positive effect of the proportional cost component, provided that the goods are normal. We also demonstrate that the effects of both the unit cost and of the proportional cost on group demand can be additively decomposed into a substitution and an income effect, and thus may be written in the form of the familiar Slutsky equation. Thus we have the two versions of the Slutsky equation for group demand. 
This result sheds new light on the law of demand, especially on the Giffen phenomenon. ${ }^{3}$ In this field, it is common to treat a good with varieties (e. g., high quality apples and low quality apples) as a single, aggregate commodity (apples), and then to consider price effects on this aggregate commodity. In this case, the Giffen phenomenon can arise only when the commodity is an inferior good. However, that analysis disregards the intra-group substitution among varieties. Our analysis shows that if we take account of such an interaction, inferiority is no longer necessary for a commodity (with varieties) to have an upward-sloping demand curve. Thus, the concept of the Slutsky equation for group demand may revise the traditional understanding of price effects.

To illustrate this, consider the following example. Following the approach of Hildenbrand (1983), Baruch and Kannai (2002) provided a case where a necessary condition for violating the law of demand, namely, a condition that the average income effect term is negative, is satisfied; in particular, they found that in Japan in the 1980s, shochu, a Japanese distilled alcoholic beverage, meets this condition (that is, shochu might be a Giffen good in the standard sense). ${ }^{4}$ Yet, since shochu is a generic commodity with varieties, it is natural to consider simultaneous price changes for the varieties of shochu, unless we consider one variety of shochu only. With several varieties of shochu, it matters whether for each pair of those varieties the relative price of a more expensive shochu for a less expensive shochu increases or decreases.

We may apply this shochu example in the framework of commodity taxation. Given the plausible assumption that alcohol is a complement to leisure, the untaxed good, our results show that the substitution effect of an increase in an ad valorem tax for shochu is positive. Then, together with the empirical inferiority of shochu, mentioned above, it follows (from Proposition 3) that the demand curve for shochu must be upward-sloping when price changes are caused by a common ad valorem tax. This means that an increase in the ad valorem tax leads

${ }^{3}$ For a survey on the law of demand, see, e. g., Jerison and Quah (2008).

${ }^{4}$ For a recent study on Giffen goods, see also Jensen and Miller (2008). 
to a higher public revenue. This result can be applied to any inferior good (with varieties) complementary to leisure, and thus seems to be helpful for both an explanation of the Giffen phenomenon and for the design of tax policies.

As a conclusion, we suggest the importance and necessity of taking into account intra-group substitution, namely substitution between varieties of a generic commodity, for it may lead to qualitatively different implications from the conventional analysis of price effects where those varieties are treated as a single (aggregate) commodity.

The rest of this paper is organized as follows. In Section 2 we set up the model. We then analyze the substitution effects of both the unit cost and of the proportional cost on group demand in Section 3 and the income effects in Section 4. We next apply these results to commodity taxation in Section 5. Finally, we conclude in Section 6.

\section{SetTing}

Consider the standard expenditure minimization problem with $n$ goods. We denote the commodity vector by $\mathbf{x}:=\left(x_{1}, x_{2}, \ldots, x_{n}\right) \in \mathbb{R}_{+}^{n}$. Suppose that the first $k$ goods are categorized into a fixed group of goods. We may think of this group as a set of similar goods the quantities of which can all be expressed in the same unit of measurement; for example, different varieties of the same basic good can be suitably aggregated in this way. Accordingly, we may refer to such a group of goods as a compound commodity, as opposed to, but in analogy with, the notion of a composite commodity. ${ }^{5}$ All goods of this group are subject to a unit cost $t \geqq 0$ and a proportional $\operatorname{cost} \tau>0$. Letting $p_{i}>0$ be the (net) prices of the goods, the gross consumer prices are given by $q_{1} \equiv$

\footnotetext{
${ }^{5}$ Since the case of $k=1$ is trivial, we focus only on the case of $k \geqq 2$. For convenience, we speak of a compound commodity even in the case of $k=n$, where all goods are categorized into a single group.
} 
$\tau p_{1}+t, \ldots, q_{k} \equiv \tau p_{k}+t, q_{k+1} \equiv p_{k+1}, \ldots, q_{n} \equiv p_{n}$, or in vector notation, $\mathbf{q}:=\left(q_{1}, \ldots, q_{k}, q_{k+1}, \ldots, q_{n}\right){ }^{6}$ Assume that a consumer has continuous, locally non-satiated, and strictly convex preferences, represented by a utility function $u: \mathbb{R}_{+}^{n} \rightarrow \mathbb{R}$. We then denote the compensated (or Hicksian) demand function, as a function of the prices $\mathbf{q}$ and the utility level $v$, by $\mathbf{x}^{*}(\mathbf{q}, v)$, and define the compensated demand function for the compound commodity as $z^{*}(\mathbf{q}, v):=\sum_{i=1}^{k} x_{i}^{*}(\mathbf{q}, v)$.

We are interested in the effects of the unit $\operatorname{cost} t$ and the proportional $\cos t \tau$ on the compensated demand for the compound commodity, $z^{*}(\mathbf{q}(t, \tau), v)$. Our interest is thus different from Hicks' (1939) composite commodity theorem where a "composite commodity" refers to the total expenditure on a group of commodities, $\sum_{i=1}^{k} p_{i} x_{i}$ (in our notation). ${ }^{7}$ To avoid confusion, we use the term "compound commodity" for $\sum_{i=1}^{k} x_{i}$. Subsequently, we focus on interior solutions, assuming the continuous differentiability of the compensated demand functions.

\section{Substitution EFFECts}

We define the expenditure function by $E(\mathbf{q}, v):=\mathbf{q} \cdot \mathbf{x}^{*}(\mathbf{q}, v)$, or as a function of the unit cost $t$, the proportional $\operatorname{cost} \tau$, the prices of the $n-k$ non-grouped commodities $\mathbf{q}_{-k} \equiv\left(q_{k+1}, \ldots, q_{n}\right)$, and the utility level $v$ by $\hat{E}\left(t, \tau, \mathbf{q}_{-k}, v\right):=E\left(\tau p_{1}+\right.$ $\left.t, \ldots, \tau p_{k}+t, q_{k+1}, \ldots, q_{n}, v\right){ }^{8}$ Similarly, rewrite the compensated demand function as $\hat{x}_{i}^{*}\left(t, \tau, \mathbf{q}_{-k}, v\right):=x_{i}^{*}\left(\tau p_{1}+t, \ldots, \tau p_{k}+t, q_{k+1}, \ldots, q_{n}, v\right)$. Thus, denote the compensated demand function for the compound commodity as $\hat{z}^{*}\left(t, \tau, \mathbf{q}_{-k}, v\right):=$ $\sum_{i=1}^{k} \hat{x}_{i}^{*}\left(t, \tau, \mathbf{q}_{-k}, v\right)$, and denote the total net (or "before tax") expenditure on

\footnotetext{
${ }^{6}$ Although we simply call $\tau$ a proportional cost, it is in fact a factor of proportional cost, and an additional cost is imposed on the group of goods only when $\tau>1$.

${ }^{7}$ For this theorem, see the literature listed in fn. 1, and also Silberberg and Suen (2001, pp. 332-335).

${ }^{8}$ For convenience, we drop the net prices $\left(p_{1}, \ldots, p_{k}\right)$ as explicit arguments. And in view of Propositions 1 and 2 and Remark 1, this practice turns out to be quite natural.
} 
the compound commodity as the function $\hat{e}^{*}\left(t, \tau, \mathbf{q}_{-k}, v\right):=\sum_{i=1}^{k} p_{i} \hat{x}_{i}^{*}\left(t, \tau, \mathbf{q}_{-k}, v\right)$. Then the function $\hat{E}$ has the same properties as the expenditure function $E$ has: ${ }^{9}$

Proposition 1. The expenditure function $\hat{E}$ has the following properties:

(i) $\hat{E}\left(t, \tau, \mathbf{q}_{-k}, v\right)$ is non-decreasing in $\left(t, \tau, \mathbf{q}_{-k}\right)$.

(ii) $\hat{E}\left(t, \tau, \mathbf{q}_{-k}, v\right)$ is homogeneous degree 1 in $\left(t, \tau, \mathbf{q}_{-k}\right)$.

(iii) $\hat{E}\left(t, \tau, \mathbf{q}_{-k}, v\right)$ is concave in $\left(t, \tau, \mathbf{q}_{-k}\right)$.

(iv) $\frac{\partial \hat{E}\left(t, \tau, \mathbf{q}_{-k}, v\right)}{\partial t}=\hat{z}^{*}\left(t, \tau, \mathbf{q}_{-k}, v\right)$

$\frac{\partial \hat{E}\left(t, \tau, \mathbf{q}_{-k}, v\right)}{\partial \tau}=\hat{e}^{*}\left(t, \tau, \mathbf{q}_{-k}, v\right)$,

$\frac{\partial \hat{E}\left(t, \tau, \mathbf{q}_{-k}, v\right)}{\partial q_{j}}=\hat{x}_{j}^{*}\left(t, \tau, \mathbf{q}_{-k}, v\right), \quad j=k+1, \ldots, n$.

Proof. See the Appendix.

Using Proposition 1, we can derive fundamental properties of the compensated demand for a compound commodity, which correspond to the properties of the compensated demand for a single good. ${ }^{10}$ To this end, we define the substitution matrix by

$$
\mathbf{S}\left(t, \tau, \mathbf{q}_{-k}, v\right):=\left(\begin{array}{ccccc}
\frac{\partial \hat{z}^{*}}{\partial t} & \frac{\partial \hat{z}^{*}}{\partial \tau} & \frac{\partial \hat{z}^{*}}{\partial q_{k+1}} & \ldots & \frac{\partial \hat{z}^{*}}{\partial q_{n}} \\
\frac{\partial \hat{e}^{*}}{\partial t} & \frac{\partial \hat{e}^{*}}{\partial \tau} & \frac{\partial \hat{e}^{*}}{\partial q_{k+1}} & \ldots & \frac{\partial \hat{e}^{*}}{\partial q_{n}} \\
\frac{\partial \hat{x}_{k+1}^{*}}{\partial t} & \frac{\partial \hat{x}_{k+1}^{*}}{\partial \tau} & \frac{\partial \hat{x}_{k+1}^{*}}{\partial q_{k+1}} & \ldots & \frac{\partial \hat{x}_{k+1}^{*}}{\partial q_{n}} \\
\vdots & \vdots & \vdots & \ddots & \vdots \\
\frac{\partial \hat{x}_{n}^{*}}{\partial t} & \frac{\partial \hat{x}_{n}^{*}}{\partial \tau} & \frac{\partial \hat{x}_{n}^{*}}{\partial q_{k+1}} & \ldots & \frac{\partial \hat{x}_{n}^{*}}{\partial q_{n}}
\end{array}\right)
$$

Proposition 2. Demand for the compound commodity and the associated substitution matrix have the following properties:

\footnotetext{
${ }^{9}$ For the standard properties of the expenditure function, see, e. g., Propositions 3.E.2 and 3.G.1 in Mas-Colell, Whinston, and Green (1995).

${ }^{10}$ For the standard properties of the compensated demand for a single good, see, e. g., Propositions 3.E.3(i) and 3.G.2 in Mas-Colell, Whinston, and Green (1995).
} 
(i) $\hat{z}^{*}\left(t, \tau, \mathbf{q}_{-k}, v\right)$ and $\hat{e}^{*}\left(t, \tau, \mathbf{q}_{-k}, v\right)$ are homogeneous degree 0 in $\left(t, \tau, \mathbf{q}_{-k}\right)$.

(ii) $\mathbf{S}\left(t, \tau, \mathbf{q}_{-k}, v\right)$ is symmetric.

(iii) $\mathbf{S}\left(t, \tau, \mathbf{q}_{-k}, v\right)$ is negative semidefinite.

(iv) $\mathbf{S}\left(t, \tau, \mathbf{q}_{-k}, v\right) \cdot\left(t, \tau, \mathbf{q}_{-k}\right)^{T}=0$.

Proof. This is proved in the usual way: (i) By Proposition 1(ii) and (iv). (ii) Using Proposition 1(iv) and applying Young's theorem, $\partial \hat{z}^{*} / \partial \tau=\partial^{2} \hat{E} / \partial \tau \partial t=$ $\partial^{2} \hat{E} / \partial t \partial \tau=\partial \hat{e}^{*} / \partial t$. And similarly for the other entries of $\mathbf{S}$. (iii) By Proposition 1(iii) and (iv). (iv) Given (i) and the fact that $\hat{x}_{i}^{*}\left(t, \tau, \mathbf{q}_{-k}, v\right)$ are homogeneous degree 0 in $\left(t, \tau, \mathbf{q}_{-k}\right)$, applying Euler's theorem yields the desired results.

Remark 1. Propositions 1 and 2 suggest that our model boils down to a model with $2+n-k$ goods, with quantities $z, e$, and $\mathbf{x}_{-k} \equiv\left(x_{k+1}, \ldots, x_{n}\right)$, and prices $t$, $\tau$, and $\mathbf{q}_{-k}$ respectively. This is since the function $\hat{E}$, which can also be expressed as $\hat{E}\left(t, \tau, \mathbf{q}_{-k}, v\right):=t \hat{z}^{*}\left(t, \tau, \mathbf{q}_{-k}, v\right)+\tau \hat{e}^{*}\left(t, \tau, \mathbf{q}_{-k}, v\right)+\sum_{i=k+1}^{n} q_{i} \hat{x}_{i}^{*}\left(t, \tau, \mathbf{q}_{-k}, v\right)$, is an expenditure function.

We see from Proposition 2(iii) that the diagonal entries of the substitution matrix $\mathbf{S}$ are non-positive. This means, in particular, that the substitution effect of the unit cost component $t$ on the compound commodity is non-positive (i.e., $\left.\partial \hat{z}^{*} / \partial t \leqq 0\right)$. This corresponds to the result presented in Silberberg and Suen (2001, pp. 335-336).

Proposition 2(iv) yields the relationship between the substitution effects of the unit cost component and of the proportional cost component:

Corollary 1 (Hicks' "third law" for a compound commodity).

$$
\frac{\partial \hat{z}^{*}\left(t, \tau, \mathbf{q}_{-k}, v\right)}{\partial t} t+\frac{\partial \hat{z}^{*}\left(t, \tau, \mathbf{q}_{-k}, v\right)}{\partial \tau} \tau+\sum_{j=k+1}^{n} \frac{\partial \hat{z}^{*}\left(t, \tau, \mathbf{q}_{-k}, v\right)}{\partial q_{j}} q_{j}=0
$$

Assume that $t>0$. Define the elasticity of the compensated demand for the compound commodity with respect to the unit cost $t$ to be $\varepsilon_{z t}^{*}:=\left(t / \hat{z}^{*}\left(t, \tau, \mathbf{q}_{-k}, v\right)\right)$ $\left(\partial \hat{z}^{*}\left(t, \tau, \mathbf{q}_{-k}, v\right) / \partial t\right)$ and define the elasticity of the compensated demand for the compound commodity with respect to the proportional cost $\tau$ to be $\varepsilon_{z \tau}^{*}:=\left(\tau / \hat{z}^{*}(t\right.$, 
$\left.\left.\tau, \mathbf{q}_{-k}, v\right)\right)\left(\partial \hat{z}^{*}\left(t, \tau, \mathbf{q}_{-k}, v\right) / \partial \tau\right)$. In addition, defining the elasticity of the compensated demand for the compound commodity with respect to the gross price $q_{j}$ to be $\varepsilon_{z j}^{*}:=\left(q_{j} / \hat{z}^{*}\left(t, \tau, \mathbf{q}_{-k}, v\right)\right)\left(\partial \hat{z}^{*}\left(t, \tau, \mathbf{q}_{-k}, v\right) / \partial q_{j}\right)$, we also get an elasticity version of Corollary 1:

Corollary 2 (Hicks' "third law” for a compound commodity in elasticity form).

$$
\varepsilon_{z t}^{*}+\varepsilon_{z \tau}^{*}+\sum_{j=k+1}^{n} \varepsilon_{z j}^{*}=0 .
$$

Acknowledging that $\varepsilon_{z t}^{*} \leqq 0$, we see from these corollaries that the substitution effect of the proportional cost component $\tau$ on the compound commodity is non-negative (i.e., $\varepsilon_{z \tau}^{*} \geqq 0$ ) either when all goods are subject to the unit and proportional cost components (i.e., $k=n$, so that $\varepsilon_{z t}^{*}+\varepsilon_{z \tau}^{*}=0$ ) or when the compound commodity and the other goods are 'on average' not substitutes (i.e., $\left.\sum_{j=k+1}^{n} \varepsilon_{z j}^{*} \leqq 0\right)$. In this sense, the substitution effect of the unit cost $t$ is basically opposite to the substitution effect of the proportional cost $\tau$. These results imply, for example, that a higher unit cost component results in a lower demand for the compound commodity, while a higher proportional cost component results in a higher demand for the compound commodity.

The positive substitution effect of the proportional cost $\tau$ seems to be a paradox at first glance, but it is not. It is in fact quite intuitive. To see this, suppose that $k=n=2$ and that $p_{1}>p_{2}$. Then an increase in $t$ reduces the relative price of the more expensive good, $q_{1} / q_{2}$, while an increase in $\tau$ raises this price, provided that $t>0::^{11}$

$$
\frac{\partial}{\partial t} \frac{q_{1}}{q_{2}}(t, \tau)=-\frac{\tau\left(p_{1}-p_{2}\right)}{\left(q_{2}\right)^{2}}<0, \quad \frac{\partial}{\partial \tau} \frac{q_{1}}{q_{2}}(t, \tau)=\frac{t\left(p_{1}-p_{2}\right)}{\left(q_{2}\right)^{2}}>0 .
$$

Consequently, an increase in $\tau$ makes the consumer substitute good 2 for good 1; but then, since good 1 is more expensive than good 2, implying that the marginal rate of substitution at the original optimal choice was greater than 1 , the

\footnotetext{
${ }^{11}$ Note that when $k=n$, the substitution effects of the unit cost $t$ and of the proportional cost $\tau$ on the compound commodity both vanish either if the unit cost is zero or if the net prices $p_{i}$ are all identical. This is simply because in these cases neither cost component affects relative prices.
} 
consumer requires more than one unit of good 2 to be compensated for sacrificing one unit of good 1. Therefore, this substitution leads to an increase in the sum of the compensated demands for goods 1 and 2. From a geometric point of view, since the budget line (and thus the indifference curve at the optimal choice $)$ is steeper than the iso-demand $\left(x_{1}+x_{2}=\right.$ constant $)$ line, an increase in $q_{1} / q_{2}$, caused by an increase in $\tau$, leads to a North-West shift of $\left(x_{1}^{*}, x_{2}^{*}\right)$ above the iso-demand line passing through the original optimal choice, that is, a shift onto a higher iso-demand line (see Figure 1).

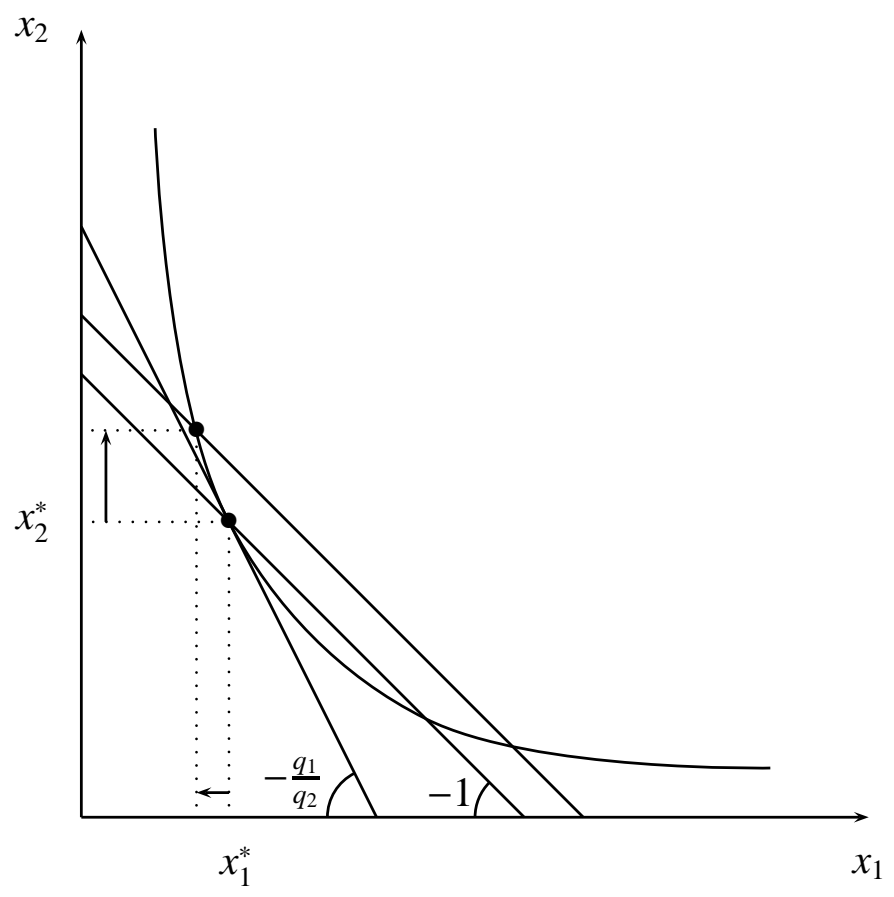

FIGURE 1. Effects of an increase in the relative price $q_{1} / q_{2}(>1)$ on the compensated demand $\left(x_{1}^{*}, x_{2}^{*}\right)$.

\section{INCOME EFFECTS}

Consider the standard utility maximization problem. We denote the ordinary (or Marshallian) demand function, as a function of the prices $\mathbf{q}$ and the (money) income $I>0$, by $\mathbf{x}^{o}(\mathbf{q}, I)$, and define the ordinary demand function for the compound commodity as $z^{o}(\mathbf{q}, I):=\sum_{i=1}^{k} x_{i}^{o}(\mathbf{q}, I)$. 
In what follows, we assume the continuous differentiability of the ordinary demand functions and analyze the effects of the unit cost $t$ and of the proportional cost $\tau$ on the ordinary demand for the compound commodity, $z^{o}(\mathbf{q}(t, \tau), I)$. Similarly to the case of the compensated demand function, rewrite the ordinary demand function as $\hat{x}_{i}^{o}\left(t, \tau, \mathbf{q}_{-k}, I\right):=x_{i}^{o}\left(\tau p_{1}+t, \ldots, \tau p_{k}+t, q_{k+1}, \ldots, q_{n}, I\right)$. Thus, denote the ordinary demand function for the compound commodity as $\hat{z}^{o}\left(t, \tau, \mathbf{q}_{-k}, I\right):=\sum_{i=1}^{k} \hat{x}_{i}^{o}\left(t, \tau, \mathbf{q}_{-k}, I\right)$. Moreover, denote the level of the ordinary demand for the compound commodity by $z^{o}:=\sum_{i=1}^{k} x_{i}^{o}$ and the level of total net (or "before tax") expenditure on the compound commodity by $e^{o}:=\sum_{i=1}^{k} p_{i} x_{i}^{o}$.

Proposition 3. (The Slutsky equations for a compound commodity).

$$
\begin{aligned}
& \frac{\partial \hat{z}^{o}\left(t, \tau, \mathbf{q}_{-k}, I\right)}{\partial t}=\frac{\partial \hat{z}^{*}\left(t, \tau, \mathbf{q}_{-k}, v\right)}{\partial t}-\frac{\partial \hat{z}^{o}\left(t, \tau, \mathbf{q}_{-k}, I\right)}{\partial I} z^{o}, \\
& \frac{\partial \hat{z}^{o}\left(t, \tau, \mathbf{q}_{-k}, I\right)}{\partial \tau}=\frac{\partial \hat{z}^{*}\left(t, \tau, \mathbf{q}_{-k}, v\right)}{\partial \tau}-\frac{\partial \hat{z}^{o}\left(t, \tau, \mathbf{q}_{-k}, I\right)}{\partial I} e^{o} .
\end{aligned}
$$

Proof. This is proved in the usual way: We obtain from a familiar duality result the identity $\hat{z}^{*}\left(t, \tau, \mathbf{q}_{-k}, v\right) \equiv \hat{z}^{o}\left(t, \tau, \mathbf{q}_{-k}, \hat{E}\left(t, \tau, \mathbf{q}_{-k}, v\right)\right)$. Differentiating both sides of this identity with respect to $t$ yields $\partial \hat{z}^{*} / \partial t=\partial \hat{z}^{o} / \partial t+\left(\partial \hat{z}^{o} / \partial I\right)(\partial \hat{E} / \partial t)$. Applying Proposition 1(iv) and using the above identity, we obtain the first equation. The second one is similarly derived.

Remark 2. Suppose that the consumer has a positive endowment in at least one good, i. e., $I \equiv \sum_{i=1}^{n} q_{i} \omega_{i}+m$ where the $\omega_{i}$ 's are non-negative initial endowments for the $n$ goods and $m$ is a positive money income. Then, Proposition 3 can be rewritten to accommodate endowment effects in addition to income effects. ${ }^{12}$

Since the substitution effect of the unit cost is non-positive by Proposition 2, Proposition 3 shows that if the ordinary demand for the compound commodity reacts positively to an increase in income, that is, if the compound commodity is a normal good (or if the considered commodities are 'on average' normal goods), the total effect of the unit cost is negative. In this sense, the substitution effect of the unit cost is reinforced if we take income effects into account.

\footnotetext{
${ }^{12}$ For the Slutsky equation with endowment effects, see, e. g., Cornwall (1984, p. 749).
} 
If, however, the ordinary demand for the compound commodity reacts negatively to an increase in income, that is, if the compound commodity is inferior (or if the considered commodities are 'on average' inferior goods), the total effect may be either negative or positive. In the latter case, the compound commodity may be regarded as a Giffen good. ${ }^{13}$

On the other hand, basically, the presence of income effects does not reinforce but mitigates the effects of the proportional cost component characterized by Corollaries 1 and 2, provided that the compound commodity is a normal good. Since a proportional cost component may have a positive effect on the compensated demand for the compound commodity, and higher costs reduce the income, the income effect counteracts the substitution effect if the compound commodity is a normal good. Thus, the total effect may be positive even when the compound commodity is a normal good. This suggests that inferiority is not necessary for a compound commodity to have an upward-sloping demand curve. Only if the compound commodity is an inferior good does the income effect work in parallel with the substitution effect provided that the latter is positive.

Assume that $t>0$. Define the elasticity of the ordinary demand for the compound commodity with respect to the unit cost $t$ to be $\varepsilon_{z t}:=\left(t / \hat{z}^{o}\left(t, \tau, \mathbf{q}_{-k}, I\right)\right)\left(\partial \hat{z}^{o}\right.$ $\left.\left(t, \tau, \mathbf{q}_{-k}, I\right) / \partial t\right)$, and the income elasticity of the ordinary demand for the compound commodity to be $\varepsilon_{z I}:=\left(I / z^{o}(\mathbf{q}, I)\right)\left(\partial z^{o}(\mathbf{q}, I) / \partial I\right)$. Moreover, define the share of the unit cost for the compound commodity in income to be $\eta_{z t}:=t z^{o} / I$. Similarly, define the elasticity of the ordinary demand for the compound commodity with respect to the proportional cost $\tau$ to be $\varepsilon_{z \tau}:=\left(\tau / \hat{z}^{o}\left(t, \tau, \mathbf{q}_{-k}, I\right)\right)\left(\partial \hat{z}^{o}(t\right.$,

\footnotetext{
${ }^{13}$ When $k=n$, at least one element of the (finite) series $S_{i}:=(\partial / \partial I) \sum_{j=1}^{i} x_{j}^{o}, i=1,2, \ldots, n$ must be positive. This may be verified as follows. Suppose that $p_{1} \geqq p_{2} \geqq \cdots \geqq p_{n}$. Set $\Delta p_{i} \equiv$ $\tau\left(p_{i}-p_{i+1}\right), i=1,2, \ldots, n-1$. Then, $q_{i}(i=1,2, \ldots, n-1)$ can be expressed as $\sum_{j=i}^{n-1} \Delta p_{j}+q_{n}$. Now, differentiating both sides of the budget constraint $\sum_{i=1}^{n} q_{i} x_{i}^{o} \equiv I$ with respect to $I$ yields $\sum_{i=1}^{n} q_{i}\left(\partial x_{i}^{o} / \partial I\right)=1$, which can be written as: $\sum_{i=1}^{n-1} \Delta p_{i} \sum_{j=1}^{i}\left(\partial x_{j}^{o} / \partial I\right)+q_{n} \sum_{j=1}^{n}\left(\partial x_{j}^{o} / \partial I\right)=1$. Since $\Delta p_{i} \geqq 0$ and $q_{n}>0$, all of $\sum_{j=1}^{i}\left(\partial x_{j}^{o} / \partial I\right), i=1,2, \ldots, n$ cannot be non-positive. This means, when $k=n=2$, if the sum of the ordinary demands for goods 1 and 2 reacts negatively to an increase in income, then the more expensive good cannot be an inferior good.
} 
$\left.\tau, \mathbf{q}_{-k}, I\right) / \partial \tau$ ). Moreover, define the (gross) share of the proportional cost for the compound commodity in income to be $\eta_{z \tau}:=\tau e^{o} / I .{ }^{14}$ Then, as a convention, we get the elasticity forms of the above two formulae:

Corollary 3 (The Slutsky equations for a compound commodity in elasticity form).

$$
\begin{aligned}
& \varepsilon_{z t}=\varepsilon_{z t}^{*}-\eta_{z t} \varepsilon_{z I}, \\
& \varepsilon_{z \tau}=\varepsilon_{z \tau}^{*}-\eta_{z \tau} \varepsilon_{z I} .
\end{aligned}
$$

These equations suggest that the difference between the uncompensated and compensated elasticities of the demand for a compound commodity with respect to each cost will be small, ceteris paribus, if either the share of each cost for the compound commodity in income is small, ${ }^{15}$ or if the income elasticity of the ordinary demand for the compound commodity is small.

\section{Application}

There is a conventional wisdom in economics that taxing a good reduces its consumption (see, e. g., Cournot, 1838, Chap. VI); more specifically, the substitution effect of an increase in the price of a good, caused by an increase in taxes, always decreases the demand for that good (see, e.g., Stiglitz, 2000, Chap. 19). While one may believe that the standard tax effects on a single good carry over to the case of a group of closely related goods, our results in the previous sections suggest that such a presumption is misguided.

To see this, consider excise (or commodity) taxes on specific goods such as gasoline, cigarettes, alcohol etc. Most of these goods have different varieties, e. g., grades of gasoline, brands of cigarettes, qualities of wine etc., and those varieties are, from an economic perspective, closely related in consumption (usually they are close substitutes); also, they are typically measured in the

\footnotetext{
${ }^{14}$ The term "gross" means that the numerator $\tau e^{o}$ includes the net expenditure on the compound commodity. See also fn. 6 .

${ }^{15}$ This is analogous to a common argument of a vanishing magnitude of the income term in the Slutsky equation. For this argument, see also Vives (1987).
} 
same units, and may thus easily be subsumed. For these reasons, different varieties are commonly treated in the same way by tax laws, and are therefore subject to the same tax rates. Accordingly, changes in the rules of taxation (i. e., in the tax rates) affect all of those varieties in parallel. Then, by specifying the unit and proportional cost components in our price specification $q_{i}=\tau p_{i}+t$ as unit and ad valorem taxes respectively, we can see that all the results in the previous sections directly apply.

Since no a priori restrictions are placed on the sign of income effects, we summarize the substitution effects of the unit tax and of the ad valorem tax in the following. Assuming that both unit and ad valorem taxes are present, we obtain: (i) the substitution effect of the unit tax on the compound commodity is nonpositive, and (ii) the substitution effect of the ad valorem tax on the compound commodity is non-negative either when all goods are subject to the unit and ad valorem taxes or when the compound commodity and the other goods are 'on average' not substitutes. Moreover, if there is no common unit tax, we find: (iii) the substitution effect of the ad valorem tax on the compound commodity is zero when all goods are subject to the ad valorem taxes, and it is again nonnegative when the compound commodity and the other goods are 'on average' not substitutes. ${ }^{16}$

Finally, it should be noted that in some countries (such as the US, Germany, and Japan) an ad valorem tax (such as the sales tax, the VAT, the consumption tax, etc.) usually applies to the full selling price including unit taxes. Then, the tax specification can be expressed in our notation as $q_{i}=\tau\left(p_{i}+t\right)$. In this case, the substitution effect of the ad valorem tax on the compound commodity -again - is zero when all goods are subject to the ad valorem taxes, and it is nonnegative when the compound commodity and the other goods are 'on average' not substitutes. Our specification, i. e., $q_{i}=\tau p_{i}+t$, is effective, for example,

\footnotetext{
${ }^{16}$ While the former implication that ad valorem taxes induce no substitution effects is well known in economics (cf. fn. 11), the latter one seems to be not recognized but may be important: it means, for example, that a higher ad valorem tax on goods complementary to leisure (untaxed good) results in a higher demand for the compound commodity.
} 
in case of gasoline in Michigan where the sales tax does not apply to the state excise tax, and in case of diesel fuel in Japan where the consumption tax (ad valorem tax) does not apply to the diesel fuel transaction tax (unit tax).

\section{Conclusion}

If a single good is subject to both unit and proportional costs, increases in the unit cost and in the proportional cost both lead to an increase in the relative price of that good; therefore the own-substitution effects of the unit cost and of the proportional cost are both non-positive. On the other hand, if a group of goods, namely a compound commodity, is subject to both unit and proportional costs, these cost components affect relative prices differently: for any given pair of those goods an increase in the unit (respectively, proportional) cost decreases (respectively, increases) the relative price of a more expensive good for a less expensive good. Accordingly, the substitution effects of the unit cost and of the proportional cost for the compound commodity may have conflicting implications.

Since the substitution effect of the unit cost for a compound commodity is non-positive, the compound commodity has the property of a single good; hence, regarding the compound commodity as a single (aggregate) commodity is justified, as argued by Silberberg and Suen (2001). On the other hand, since the substitution effect of the proportional cost for a compound commodity may be non-negative, a compound commodity generally does not have the properties of a single good. Therefore, when variations in proportional cost components are considered, a compound commodity cannot simply, i.e., without qualification, be treated as a single (aggregate) commodity.

Consequently, when we consider the effects of simultaneous price changes on a compound commodity, it is imperative to inspect the induced changes in the relative prices. Ignoring this inspection and simply analyzing the compound commodity as if it were a single (aggregate) commodity may lead to seriously 
flawed conclusions and interpretations. Actually, price changes affect the relative prices even if these prices share a common cost component, a change in which modifies all prices simultaneously. A change in the common cost components, such as taxes or transportation costs, modifies relative prices. In particular, changes in unit or ad valorem taxes imposed on all varieties of a generic commodity affect the relative prices among these varieties. Yet, then, the properties for the demand of a single good do not generically hold for the demand for the compound commodity. Thus, we should be careful about aggregation when analyzing price effects on a generic commodity with varieties.

\section{APPENDIX}

Proof of Proposition 1. This is proved in the usual way: (i) Suppose that $t^{\prime \prime} \geqq t^{\prime}, \tau^{\prime \prime} \geqq \tau^{\prime}$, and $\mathbf{q}_{-k}^{\prime \prime} \geqq \mathbf{q}_{-k}^{\prime}{ }^{17}$ Then, $\hat{E}\left(t^{\prime \prime}, \tau^{\prime \prime}, \mathbf{q}_{-k}^{\prime \prime}, v\right)=\sum_{i=1}^{k}\left(\tau^{\prime \prime} p_{i}+\right.$ $\left.t^{\prime \prime}\right) \hat{x}_{i}^{*}\left(t^{\prime \prime}, \tau^{\prime \prime}, \mathbf{q}_{-k}^{\prime \prime}, v\right)+\sum_{i=k+1}^{n} q_{i}^{\prime \prime} \hat{x}_{i}^{*}\left(t^{\prime \prime}, \tau^{\prime \prime}, \mathbf{q}_{-k}^{\prime \prime}, v\right) \geqq \sum_{i=1}^{k}\left(\tau^{\prime} p_{i}+t^{\prime}\right) \hat{x}_{i}^{*}\left(t^{\prime \prime}, \tau^{\prime \prime}, \mathbf{q}_{-k}^{\prime \prime}, v\right)+$ $\sum_{i=k+1}^{n} q_{i}^{\prime} \hat{x}_{i}^{*}\left(t^{\prime \prime}, \tau^{\prime \prime}, \mathbf{q}_{-k}^{\prime \prime}, v\right) \geqq \sum_{i=1}^{k}\left(\tau^{\prime} p_{i}+t^{\prime}\right) \hat{x}_{i}^{*}\left(t^{\prime}, \tau^{\prime}, \mathbf{q}_{-k}^{\prime}, v\right)+\sum_{i=k+1}^{n} q_{i}^{\prime} \hat{x}_{i}^{*}\left(t^{\prime}, \tau^{\prime}, \mathbf{q}_{-k}^{\prime}, v\right)$ $=\hat{E}\left(t^{\prime}, \tau^{\prime}, \mathbf{q}_{-k}^{\prime}, v\right)$. That is, $\hat{E}\left(t^{\prime \prime}, \tau^{\prime \prime}, \mathbf{q}_{-k}^{\prime \prime}, v\right) \geqq \hat{E}\left(t^{\prime}, \tau^{\prime}, \mathbf{q}_{-k}^{\prime}, v\right)$. (ii) For $\theta>0$, $\hat{E}\left(\theta t, \theta \tau, \theta \mathbf{q}_{-k}, v\right)=\sum_{i=1}^{k}\left(\theta \tau p_{i}+\theta t\right) \hat{x}_{i}^{*}\left(\theta t, \theta \tau, \theta \mathbf{q}_{-k}, v\right)+\sum_{i=k+1}^{n} \theta q_{i} \hat{x}_{i}^{*}\left(\theta t, \theta \tau, \theta \mathbf{q}_{-k}, v\right)=$ $\sum_{i=1}^{k} \theta\left(\tau p_{i}+t\right) \hat{x}_{i}^{*}\left(t, \tau, \mathbf{q}_{-k}, v\right)+\sum_{i=k+1}^{n} \theta q_{i} \hat{x}_{i}^{*}\left(t, \tau, \mathbf{q}_{-k}, v\right)=\theta \hat{E}\left(t, \tau, \mathbf{q}_{-k}, v\right)$. That is, $\hat{E}\left(\theta t, \theta \tau, \theta \mathbf{q}_{-k}, v\right)=\theta \hat{E}\left(t, \tau, \mathbf{q}_{-k}, v\right)$. (iii) Set that $t^{\theta} \equiv \theta t^{\prime}+(1-\theta) t^{\prime \prime}, \tau^{\theta} \equiv$ $\theta \tau^{\prime}+(1-\theta) \tau^{\prime \prime}$, and $\mathbf{q}_{-k}^{\theta} \equiv \theta \mathbf{q}_{-k}^{\prime}+(1-\theta) \mathbf{q}_{-k}^{\prime \prime}$ where $\theta \in[0,1]$. Then, $\hat{E}\left(t^{\prime}, \boldsymbol{\tau}^{\prime}, \mathbf{q}_{-k}^{\prime}, v\right) \leqq$ $\sum_{i=1}^{k}\left(\tau^{\prime} p_{i}+t^{\prime}\right) \hat{x}_{i}^{*}\left(t^{\theta}, \tau^{\theta}, \mathbf{q}_{-k}^{\theta}, v\right)+\sum_{i=k+1}^{n} q_{i}^{\prime} \hat{x}_{i}^{*}\left(t^{\theta}, \tau^{\theta}, \mathbf{q}_{-k}^{\theta}, v\right)$ and $\hat{E}\left(t^{\prime \prime}, \tau^{\prime \prime}, \mathbf{q}_{-k}^{\prime \prime}, v\right) \leqq$ $\sum_{i=1}^{k}\left(\tau^{\prime \prime} p_{i}+t^{\prime \prime}\right) \hat{x}_{i}^{*}\left(t^{\theta}, \tau^{\theta}, \mathbf{q}_{-k}^{\theta}, v\right)+\sum_{i=k+1}^{n} q_{i}^{\prime \prime} \hat{x}_{i}^{*}\left(t^{\theta}, \tau^{\theta}, \mathbf{q}_{-k}^{\theta}, v\right)$. Thus, $\theta \hat{E}\left(t^{\prime}, \tau^{\prime}, \mathbf{q}_{-k}^{\prime}, v\right)+$ $(1-\theta) \hat{E}\left(t^{\prime \prime}, \tau^{\prime \prime}, \mathbf{q}_{-k}^{\prime \prime}, v\right) \leqq \theta\left[\sum_{i=1}^{k}\left(\tau^{\prime} p_{i}+t^{\prime}\right) \hat{x}_{i}^{*}\left(t^{\theta}, \tau^{\theta}, \mathbf{q}_{-k}^{\theta}, v\right)+\sum_{i=k+1}^{n} q_{i}^{\prime} \hat{x}_{i}^{*}\left(t^{\theta}, \tau^{\theta}, \mathbf{q}_{-k}^{\theta}, v\right)\right]$ $+(1-\theta)\left[\sum_{i=1}^{k}\left(\tau^{\prime \prime} p_{i}+t^{\prime \prime}\right) \hat{x}_{i}^{*}\left(t^{\theta}, \tau^{\theta}, \mathbf{q}_{-k}^{\theta}, v\right)+\sum_{i=k+1}^{n} q_{i}^{\prime \prime} \hat{x}_{i}^{*}\left(t^{\theta}, \tau^{\theta}, \mathbf{q}_{-k}^{\theta}, v\right)\right]=\sum_{i=1}^{k}\left(\tau^{\theta} p_{i}+\right.$ $\left.t^{\theta}\right) \hat{x}_{i}^{*}\left(t^{\theta}, \tau^{\theta}, \mathbf{q}_{-k}^{\theta}, v\right)+\sum_{i=k+1}^{n} q_{i}^{\theta} \hat{x}_{i}^{*}\left(t^{\theta}, \tau^{\theta}, \mathbf{q}_{-k}^{\theta}, v\right)=\hat{E}\left(t^{\theta}, \tau^{\theta}, \mathbf{q}_{-k}^{\theta}, v\right)$. That is, $\theta \hat{E}\left(t^{\prime}, \tau^{\prime}\right.$, $\left.\mathbf{q}_{-k}^{\prime}, v\right)+(1-\theta) \hat{E}\left(t^{\prime \prime}, \tau^{\prime \prime}, \mathbf{q}_{-k}^{\prime \prime}, v\right) \leqq \hat{E}\left(t^{\theta}, \tau^{\theta}, \mathbf{q}_{-k}^{\theta}, v\right)$. (iv) The Lagrangian for the expenditure minimization problem is $L\left(\mathbf{x}, \lambda ; t, \tau, \mathbf{q}_{-k}, v\right):=\mathbf{q} \cdot \mathbf{x}+\lambda[v-u(\mathbf{x})]$. By applying the envelope theorem to this problem, we have $\partial \hat{E} / \partial t=\partial L / \partial t=$

\footnotetext{
${ }^{17}$ We write $\mathbf{q}_{-k}^{\prime \prime} \geqq \mathbf{q}_{-k}^{\prime}$ whenever $q_{j}^{\prime \prime} \geqq q_{j}^{\prime}, j=k+1, \ldots, n$.
} 
$\sum_{i=1}^{k} \hat{x}_{i}^{*}=\hat{z}^{*}$ and $\partial \hat{E} / \partial \tau=\partial L / \partial \tau=\sum_{i=1}^{k} p_{i} \hat{x}_{i}^{*}=\hat{e}^{*}$. The final property is immediate.

\section{REFERENCES}

A. A. Alchian and W. R. Allen. University Economics. Wadsworth, Belmont, California, 1964.

S. Baruch and Y. Kannai. Inferior goods, Giffen goods, and shochu. In: G. Debreu, W. Neuefeind, and W. Trockel (eds.) Economics Essays. Springer, Berlin, 2002.

M. Carter. An expository note on the composite commodity theorem. Economic Theory, 5(1): 175-179, 1995.

R. R. Cornwall. Introduction to the Use of General Equilibrium Analysis. NorthHolland, Amsterdam, 1984.

A. A. Cournot. Researches into the Mathematical Principles of the Theory of Wealth. English edition of Recherches sur les Principes Mathématiques de la Théorie des Richesses. Kelley, New York, 1838.

G. C. Davis. The generalized composite commodity theorem: Stronger support in the presence of data limitations. Review of Economics and Statistics, 85(2): 476-480, 2003.

A. Deaton and J. Muellbauer. Economics and Consumer Behavior. Cambridge University Press, Cambridge, 1980.

H. A. J. Green. Consumer Theory. Revised edition, Macmillan, London, 1976.

J. R. Hicks. Value and Capital. Clarendon Press, Oxford, 1939.

W. Hildenbrand. On the Law of Demand. Econometrica, 51(4): 997-1019, 1983.

D. Hummels and A. Skiba. Shipping the good apples out? An empirical confirmation of the Alchian-Allen conjecture. Journal of Political Economy, 112(6): 1384-1402, 2004.

R. T. Jensen and N. H. Miller. Giffen Behavior and Subsistence Consumption. American Economic Review, 98(4): 1553-1577, 2008.

M. Jerison and J. K.-H. Quah. The Law of Demand. The New Palgrave Dictionary of Economics. Second edition, 2008. 
D. W. Katzner. Static Demand Theory. Macmillan, Toronto, 1970.

A. Lewbel. Aggregation without separability: A generalized composite commodity theorem. American Economic Review, 86(3): 524-543, 1996.

A. Mas-Colell, M. D. Whinston, and J. R. Green. Microeconomic Theory. Oxford University Press, New York, 1995.

J. Minagawa and T. Upmann. The generalized Alchian-Allen theorem: A Slutsky equation for relative demand. Economic Inquiry, 53(4): 1893-1907, 2015.

D. Moro. Aggregation without separability: Composite commodity theorems in quantity-space. Economics Letters, 71(1): 67-73, 2001.

R. A. Musgrave. The Theory of Public Finance. McGraw-Hill, New York, 1959.

P. A. Samuelson. Foundations of Economic Analysis. Harvard University Press, Cambridge, 1947.

E. Silberberg and W. Suen. The Structure of Economics: A Mathematical Analysis. Third edition. McGraw-Hill, New York, 2001.

J. E. Stiglitz. Economics of the Public Sector. Third edition. W. W. Norton \& Company, New York, 2000.

X. Vives. Small income effects: A Marshallian theory of consumer surplus and downward sloping demand. Review of Economic Studies, 54(1): 87-103, 1987. 